\title{
Utilization of tuna roe and using inulin as oil replacer for producing value added omega-3 mayonnaise product
}

\author{
Kanrawee Hunsakul, Sunisa Siripongvutikorn*, and Worapong Usawakesmanee \\ Department of Food Technology, Faculty of Agro-Industry, Prince of Songkla University, \\ Hat Yai, Songkhla 90112, Thailand
}

*Corresponding Author: Sunisa Siripongvutikorn, PhD, Asst. Professor, Department of Food Technology, Faculty of Agro-Industry, Prince of Songkla University, Hat Yai, Songkhla, 90112, Thailand

Submission date: January 15, 2016; Acceptance date: March 24, 2016: Publication date: March 26, 2016

\begin{abstract}
Background: The fishery industry has been important for Thailand's economy for more than 30 years. For example, Thailand is the world's largest canned tuna producer and exporter. However, only ordinary meat or white meat is used for raw material in canned tuna products. While roe, viscera, head and dark meat are sold at cheap prices, with these by-products being used to feed plant or local human food, its nutritive values with fat, protein and minerals are still high. It is well known that tuna is a good source of polyunsaturated fatty acid (PUFA), including Eicosapentaenoic acid (EPA) and Docosahexanoic acid (DHA). People around the world pay more attention to eating salads consisting of fruits and vegetables, in addition to dressing. Generally, mayonnaise, a kind of salad dressing, consists of chicken egg yolk (12-15\%) and soybean oil (30-65\%). Both of these ingredients contain very high saturated fatty acid contents. Therefore, because normal mayonnaise is high in fat content and low in polyunsaturated fatty acid, this product is not ideal for people on a diet or those who are trying to control their weight.
\end{abstract}

Objective: To increase omega-3 through tuna roe substitution and to replace fat content using inulin gel.

Methods: Tuna roe was prepared by soaking in galangal solution extracted with $95 \%$ ethanol for removal fishy/rancidity odor. Inulin powder $45 \mathrm{~g}$ was suspended in $55 \mathrm{ml}$ of water before being brought to heat at temperature $80^{\circ} \mathrm{C}$ for $30 \mathrm{~min}$ to form a gel and stored at $4^{\circ} \mathrm{C}$. Treatment of making omega-3 mayonnaise product was started using $100 \%$ tuna roe substitution for egg yolk. Thereafter, inulin gel was added to replace vegetable oil at 0, 25, 50, 75 and 100\%. Basic mayonnaise containing egg yolk and $0 \%$ inulin gel (100\% soy bean oil) was used as the control sample. Color and emulsion stability tests were monitored for physical quality. $\mathrm{pH}$ value, peroxide value (PV) and thiobarbituric acid reactive substances (TBARS) were used for 
chemical quality analyses. Total viable count (TVC), yeast and mold, lactic acid bacteria (LAB) and coliforms were measured for microbiological quality. Sensory evaluation using 9-point hedonic scale technique was also monitored.

Results: When there was increased inulin gel in the mayonnaise, $L^{*}$ value significantly increased while $a^{*}$ and $b^{*}$ values significantly decreased $(p<0.05)$. Without addition of inulin gel, tuna roe mayonnaise (IG0) had lower emulsion stability compared with control sample containing egg yolk. It was found that using the inulin gel significantly increased moisture contents and water activity of the mayonnaise. However, there was no significantly difference found in $\mathrm{pH}$ value in any sample. In addition, the tuna roe mayonnaise with and without added inulin gel possessed higher lipid oxidation products determined as PV and TBARS value compared with basic mayonnaise using egg yolk (control sample). All microbiological quality indices were very low and passed through a standard regulation of mayonnaise product. Although consumer acceptability of the mayonnaise producing from tuna roe was lower than that of control, 50\% of inulin gel substitution (IG50) seemed to obtain higher sensory score when compared with other inulin gel substitution groups. Therefore, sensory improvement of the tuna roe mayonnaise product substituted with inulin gel needs to be studied further.

Conclusions: The mayonnaise produced from tuna roe and replaced fat with inulin gel between 25 to $100 \%$ were successful when determined by emulsion stability, $\mathrm{pH}$ value and microbiological quality. However, sensory score of the mayonnaise using $100 \%$ tuna roe with and without inulin gel substitution was lower than that of control. The tuna roe mayonnaise substituted with 50\% inulin gel (IG50) should be selected for sensory improvement in the further work.

Keywords: Tuna roe, Mayonnaise, Inulin, Omega-3

\section{BACKGROUND}

Thailand has been claimed as the world's largest canned tuna producers and exporters for more than 30 years. By the year 2012, the amount of tuna products exported from Thailand was $559,492.77$ tons with value of $82,598.28$ million baht or 2,445 million USD [1]. Industry's survey data showed that the solid waste or by-product inclusion of tuna roe accounted for $1-2 \%$ of material sold at about $1 \mathrm{USD} / \mathrm{kg}$ for animal feed plant or local food shop for making the stirred fry, deep fry products and so on [2]. It is well known that tuna is a good source of polyunsaturated fatty acid (PUFA), including Eicosapentaenoic acid (EPA) and Docosahexanoic acid (DHA) [3]. However, the nature of these unsaturated n-3 PUFA is more susceptible to lipid oxidation than saturated lipids leading to the formation of undesirable off-flavours and unhealthy compounds such as free radicals and reactive aldehydes. The off-flavours formed from n-3 PUFA oxidation are particularly unpleasant. Furthermore, the human sensory apparatus has a low threshold for volatile off-flavours resulting from oxidation of n-3 PUFA [4].

Mayonnaise, an oil-in-water emulsion product, typically contains egg yolks, salt, vinegar, mustard, and flavoring materials, as well as high fat content of about $60-80 \%$. The real 
mayonnaise contains roughly $65-80 \%$ fat, whereas the "light" mayonnaise products which contains about $36 \%$ fat, is still new and has been marketed only in recent years [5]. Mayonnaise is high in fat content but low in polyunsaturated fatty acid contents. Therefore, consuming this product may not a great choice for people on a diet or controlling their weight.

Inulin is a non-digestible carbohydrate consisting mainly of fructose connected by $\beta-(2-1)$ bonds, ending with a glucose of the chain linked to the last fructose unit through an $\alpha-(1-2)$ bond [6]. Native or medium chain length inulin in chicory root composed of 3 to 60 monosaccharide units (average of about 10) [7]. Inulin is used as a bulking agent, in particular as a fat replacement, and is aided by its particular properties of water solubility. Parts of the molecular structure, specifically the hydroxyl groups, are able to interact with water more than its other parts. This provides inulin with some surfactant characteristic, which enables it to form stable gels with water at concentrations of $13-50 \%[8,9]$. The aims of this study are to substitute tuna roe for increasing omega-3 and to replace fat content by using inulin into the mayonnaise. Thereafter physical, chemical, microbiological qualities and sensory acceptability were evaluated.

\section{MATERIALS AND METHODS \\ Materials}

Roe of frozen skipjack tuna (Katsuwonous pelamis) was obtained from Songkla Canning Public Co. Ltd., Songkhla, Thailand with controlling temperature not over $15^{\circ} \mathrm{C}$ and period after viscera removal process not exceed $3 \mathrm{~h}$. The sample was kept in plastic bag, covered with ice and transported to the Faculty of Agro Industry, Prince of Songkla University within $1 \mathrm{~h}$. The sample was washed with cold water $\left(0-4^{\circ} \mathrm{C}\right)$ and kept in polyethylene bag and stored at $-20^{\circ} \mathrm{C}$ until use within 3 months.

Galangal (Alpinia galanga (L.) Willd.) rhizome with aged 12-14 months was purchased from Plaza fresh market, Hat Yai. Inulin (Orafti ${ }^{\circledR} \mathrm{HP}$ ) with degree of polymerization between 260 of chicory root was purchased from BENEO-Orafti, Thienen, Belgium.

\section{Sample preparation}

\section{Galangal extract and tuna roe preparation}

Galangal ethanolic extract (GEE): The rhizome was cut into small pieces before taken to homogenize with $95 \%$ ethanol at a ratio of plant: solvent of 10:90 (w/v) then stand for $30 \mathrm{~min}$ and filtrated through cheesecloth.

Skipjack tuna roe was scraped to remove the roe sack out. Thereafter, the roe granules were washed with cold water $\left(0-4^{\circ} \mathrm{C}\right)$ and drained on the sieve for $3 \mathrm{~min}$. The separated-washed tuna roe was soaked in the treatment as mentioned above at $4^{\circ} \mathrm{C}$ for $30 \mathrm{~min}$, at a ratio of roe: solvent/suspension as 1:3. Thereafter, sample was drained on the sieve and rinsed with distilled water for 2 times. The pre-treated tuna roe was blanched with hot water at ratio 1:3 (roe: hot water) at $65^{\circ} \mathrm{C}$ for $30 \mathrm{sec}$. The blanched sample was suddenly cooled in the ice-water $\left(4^{\circ} \mathrm{C}\right)$ for 1 min, drained then kept in polyethylene bag, stored at $4^{\circ} \mathrm{C}$ and used within $1 \mathrm{~d}$.

\section{Inulin gel preparation}


Inulin powder ( $45 \mathrm{~g}$ ) was added in to $55 \mathrm{ml}$ of water to obtain $100 \mathrm{ml}$ of final suspension before brought to heat at $80^{\circ} \mathrm{C}$ for $30 \mathrm{~min}$ to form a gel and stored at $4{ }^{\circ} \mathrm{C}$ for using in the mayonnaise within $2 \mathrm{~d}$.

\section{Mayonnaise preparation}

Mayonnaise generally consists of soy bean oil, egg yolk, sugar, vinegar, mustard and salt as 45, 15, 20,17, 2 and $1 \mathrm{~g}$, respectively for making the product $100 \mathrm{~g}$ (Table 1). To substitute fat content, inulin gel was replaced at levels of $0,25,50,75$ and $100 \%$ of total oil used. However, in this experiment, the portion of egg yolk was substituted with tuna roe, except for the control sample as showed in Table 1. After mixing all ingredients to obtain the mayonnaise, it was transferred to standing pouch, and kept at $4{ }^{\circ} \mathrm{C}$ for further analyses.

Table 1 Ingredients of mayonnaise.

\begin{tabular}{lcccccc}
\hline \multirow{2}{*}{$\begin{array}{c}\text { Ingredients } \\
\text { (g/100g product) }\end{array}$} & Traditional mayonnaise & \multicolumn{5}{c}{ High omega-3 and low fat mayonnaise } \\
\cline { 2 - 7 } Soybean oil & Control & IG0 & IG25 & IG50 & IG75 & IG100 \\
Inulin gel & 45 & 45 & 33.75 & 22.5 & 11.25 & - \\
Egg yolk & - & - & 11.25 & 22.5 & 33.75 & 45 \\
Tuna roe & 15 & - & - & - & - & - \\
Sugar & - & 15 & 15 & 15 & 15 & 15 \\
Vinegar & 20 & 20 & 20 & 20 & 20 & 20 \\
Mustard & 17 & 17 & 17 & 17 & 17 & 17 \\
Salt & 2 & 2 & 2 & 2 & 2 & 2 \\
\hline
\end{tabular}

\section{Methods}

\section{Color}

The mayonnaise samples were measured for color in the $L^{*}, a^{*}, b^{*}$ system using a colorimeter (Hunter Lab, Model Color Quest XT, United State), which was calibrated using a white standard porcelain plate $\left(L^{*}=93.6, a^{*}=-0.94\right.$ and $\left.b^{*}=0.40\right)$. In this color system, $L^{*}$ represents the lightness, and $a^{*}$ and $b^{*}$ are the color coordinates, whereby $+a$ represents the red coordinate, $-a$ is the green coordinate, $+b$ is the yellow coordinate, and $-b$ is the blue coordinate.

\section{Emulsion stability test}

Sample weighed $15 \mathrm{~g}\left(\mathrm{~F}_{0}\right)$ was transferred to the test tubes and tightly sealed with parafilm then stored at $50^{\circ} \mathrm{C}$ for $48 \mathrm{hr}$. After storage, the emulsion will be centrifuged for $10 \mathrm{~min}$ at $3000 \mathrm{x} g$ to remove the top oil layer. The weight of the precipitated fraction $\left(\mathrm{F}_{1}\right)$ was measured, and the emulsion stability was characterized as $(\%)=\left(\mathrm{F}_{1} / \mathrm{F}_{0}\right) \times 100[10]$.

\section{3. $p H$ values}

$\mathrm{pH}$ values of the mayonnaise samples were measured at a temperature of $25^{\circ} \mathrm{C}$ using $\mathrm{pH}$ meter. The samples were obtained by homogenizing $1 \mathrm{~g}$ of sample wit $10 \mathrm{ml}$ of distilled water. Three replicates from three different samples were taken for each $\mathrm{pH}$ measurement [11].

\section{Moisture content}


Samples were mixed with dried sand to prevent clumping and surface crust formation before brought to dry in an oven according to the method of AOAC [12].

\section{Water activity $\left(a_{w}\right)$}

The $a_{w}$ value of the samples was determined by using Aqua Lab Water Activity Meter (Series, WA, USA).

\section{Peroxide value (PV)}

Sample $(0.3 \mathrm{~g})$ was mixed with $1.5 \mathrm{ml}$ of isooctane: 2 -propanol $(3: 2 \mathrm{v} / \mathrm{v})$ by vortexing for $10 \mathrm{~s}$ for three times and stand for $30 \mathrm{~min}$. Thereafter, $0.2 \mathrm{ml}$ of the organic solution from upper solvent phase was withdrawn and added to $2.8 \mathrm{ml}$ mixture of chloroform: methanol (7:3 v/v), followed by $15 \mu \mathrm{l}$ of 3.94 ammonium thiocyanate and $15 \mu \mathrm{l}$ of ferrous ion solution (prepared by mixing $0.4 \mathrm{~g}$ of $\mathrm{BaCl}_{2}$ which was dissolved in $50 \mathrm{ml}$ water, with $0.5 \mathrm{~g}$ of $\mathrm{FeSO}_{4} .7 \mathrm{H}_{2} \mathrm{O}$ which was dissolved in $50 \mathrm{ml}$ water and $2 \mathrm{ml}$ of $\mathrm{HCl}$ ). The absorbance of the solution was measured at 500 $\mathrm{nm}$ for 5 min after addition of the iron solution. Peroxide concentrations were determined using a standard curve made from cumene hydroperoxide and reported as mg hydroperoxide/ $\mathrm{kg}$ sample [13].

\section{Thiobarbitiraic acid reactive substances (TBARS)}

Ten-g of sample was homogenized with $50 \mathrm{ml}$ water for $2 \mathrm{~min}$ before being brought to the distillation flask and was followed by adding $47.5 \mathrm{ml}$ of water. $2.5 \mathrm{ml}$ of $4 \mathrm{~N} \mathrm{HCl}$ was added into the flask to bring the $\mathrm{pH}$ down to 1.5 , then followed by an antifoaming agent and a few glass beads. The sample was distilled for $10 \mathrm{~min}$ to obtain $50 \mathrm{ml} .5 \mathrm{ml}$ of the distilled sample was then added with $5 \mathrm{ml}$ TBA reagent $(0.2883 \mathrm{~g} / 100 \mathrm{~g}$ of $90 \%$ glacial acetic acid $)$ and heated in boiling water for $35 \mathrm{~min}$ to develop a pink color. Afterwards, the sample was cooled down with running tap water, before being brought to measure the absorbance at $532 \mathrm{~nm}$. The results were expressed as $\mathrm{mg}$ malondialdehyde/ $\mathrm{kg}$ sample. A standard curve was prepared using 1,1,3,3tetramethoxypropane at concentrations ranging from 0 to $5 \mathrm{ppm}$ in the same manner as the sample [14].

\section{Microbiological analysis}

Twenty five-g of each sample was blended with $225 \mathrm{ml}$ of $0.1 \%$ sterilized peptone water to obtain $10^{-1}$ dilution. Other serial dilutions of $10^{-2}$ to $10^{-4}$ were prepared with $0.1 \%$ sterilized peptone water. Total viable count (TVC) was determined by pour plate method using plat count agar (PCA), and incubated at $35^{\circ} \mathrm{C}$ for $24-72 \mathrm{hr}$ [15]. Yeast and mold were determined by spread plate method using potato dextrose agar (PDA) before incubated at $30^{\circ} \mathrm{C}$ for $3-5 \mathrm{~d}$ [16]. Coliforms were determined using lauryl sulphate tryptose broth (LST) with durham tube. The tubes were incubated at $37^{\circ} \mathrm{C}$ for $24-48 \mathrm{hr}$. The tubes provided gas in durham tubes were recorded as positive objects which were then transferred into EC broth medium and incubated at $35^{\circ} \mathrm{C}$ for $24-48 \mathrm{hr}$ to determine coliform bacteria. Thereafter, the tubes showing gas production was considered positive [17]. Lactobacillus was determined using de Man Rogosa and Sharpe 
agar (MRS) by pour plate technique and incubated in anaerobic condition at $35^{\circ} \mathrm{C}$ for $48 \mathrm{hr}$ [18]. All microbial counts were expressed as CFU/g, except coliforms were expressed as MPN/g.

\section{Sensory acceptability}

The analyses performed by 30 untrained panelists. The panelists were asked to evaluate the likeness on appearance, color, odor, taste and overall acceptability of the samples by using a 9point hedonic scale (9=like extremely, $1=$ dislike extremely) [19]. The panelists were students and staff of Faculty Agro Industry, Prince of Songkla University, Hat Yai, Songkhla, Thailand. The sample $(10 \mathrm{~g})$ was served in plastic cup at $25^{\circ} \mathrm{C}$ together with toast and punctuated with cantaloupe flesh.

\section{Statistical analysis}

Completely randomized design was used throughout at this experiment. All data were subjected to Analysis of Variance (ANOVA) and the differences between means were evaluated by Duncan's Multiple Range Test [20].

\section{RESULTS AND DISCUSSION}

\section{Color}

The color of mayonnaise samples substituted with tuna roe and inulin gel at various ratios, as well as the control sample, were shown in Figure 1. The lightness $\left(\mathrm{L}^{*}\right)$, redness $\left(\mathrm{a}^{*}\right)$ and yellowness $\left(b^{*}\right)$ values of control sample were highest when compared with other samples $(\mathrm{p}<0.05)$. Regardless of control group, $\mathrm{L}^{*}$ of the tuna roe mayonnaise increased with increasing inulin gel $(\mathrm{p}<0.05)$. This may due to whiteness, which is a typical characteristic of inulin gel. Moreover, $a^{*}$ and $b^{*}$ of the samples also decreased as inulin gel increased. The color of egg yolk is attributed to fat-soluble carotenoids including lutein, zeaxanthin, $\beta$-cryptoxanthin and minor amounts of $\beta$-carotene [21], while tuna roe contained more myoglobin (dark red) pigments, which may change to be metmyoglobin (grey-brown) form due to oxidation [22]. In addition, metmyoglobin in tuna roe in this experiment should have been more generated as a resulted of blanching effect [23].

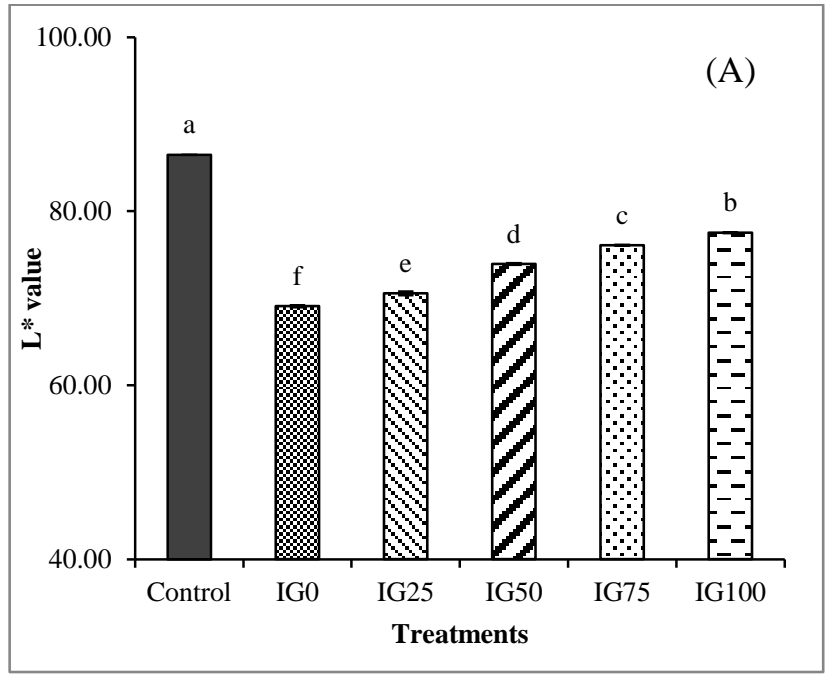




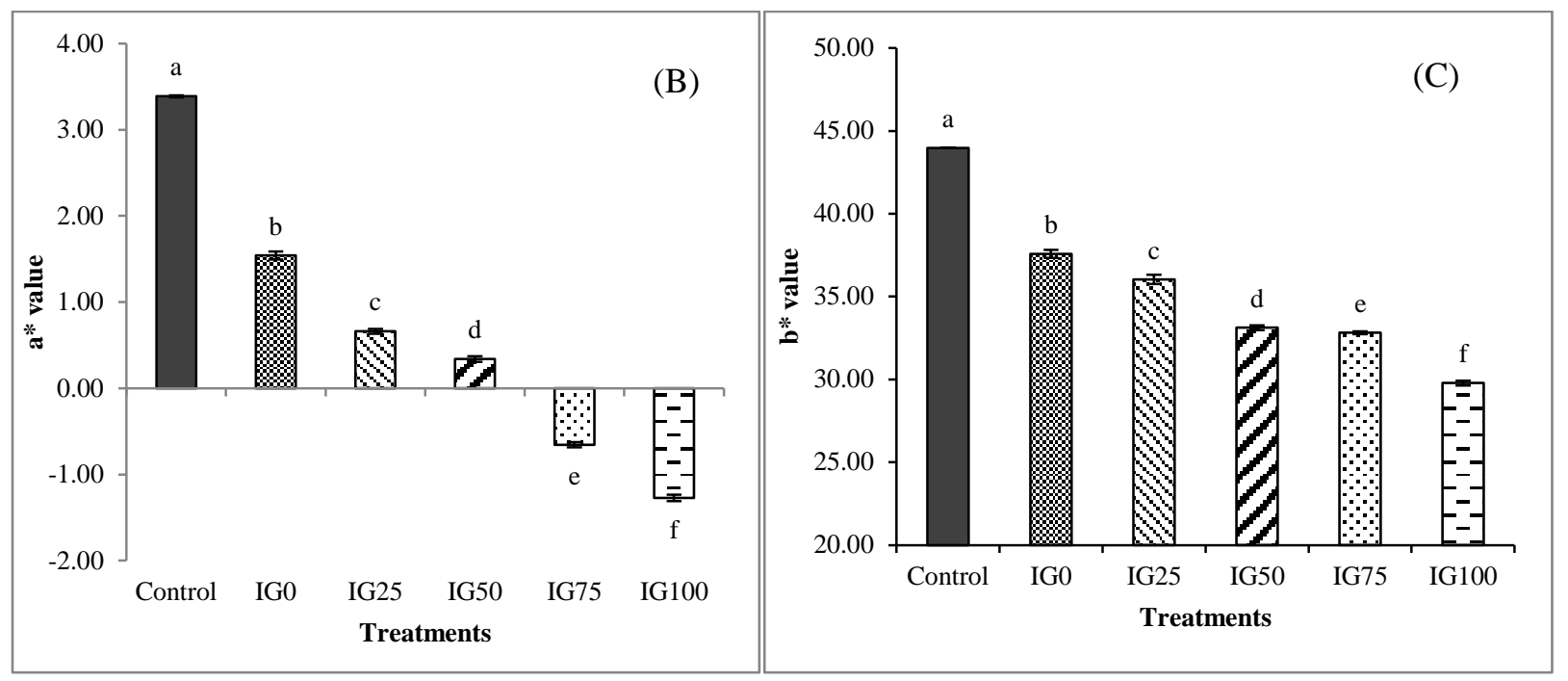

Figure 1. Lightness or $\mathrm{L}^{*}(\mathrm{~A})$, redness-greennes or $\mathrm{a}^{*}(\mathrm{~B})$ and yellowness-blueness or $\mathrm{b}^{*}(\mathrm{C})$ of tuna roe mayonnaise replacing soybean oil with inulin gel. Bars represent the standard deviation $(n=5)$. Different letters on the bars indicate significant difference $(\mathrm{p}<0.05)$.

\section{Emulsion stability}

Emulsion stability of the mayonnaise using the tuna roe and replacing soybean oil with inulin gel was shown in Figure 2. The emulsion stabilities of both control sample and tuna roe with inulin gel sample were $98.77 \%-99.80 \%$. The results showed no significant difference of emulsion stability in both the control sample and with tuna roe substituted with inulin gel. However, it was found that the stability of emulsion obtained from the tuna roe mayonnaise without inulin gel was lowest when compared with other samples. In particular, the tuna roe lost its emulsifier property because of pre-treatment including soaking and blanching effect. Basically, emulsion stability involves preventing droplet coalescence, flocculation, and creaming [10]. The products with low fat content, creaming is usually prevented by adding a thickening agent such as gum or a starch to the aqueous phase to slow down the droplet movement. Therefore, IG0 which was no inulin replacement exhibited less emulsion stability. It pointed out that inulin helped increase emulsion stability in the mayonnaise substituted with tuna roe which was prepared by soaking in GEE and blanching. The lower emulsion stability found in IG0 may be due to phospholipid and protein denaturation caused by washing, soaking and blanching process as well as without any substituted emulsifier as inulin [24]. Mun et al. [10] reported that the reduced fat mayonnaise samples showed a higher stability compared with the full fat samples due to the increased viscosity of the aqueous phase and slowed down oil droplet movement by the addition of $4 \alpha$ GTase-treated starch paste and xanthan gum. 


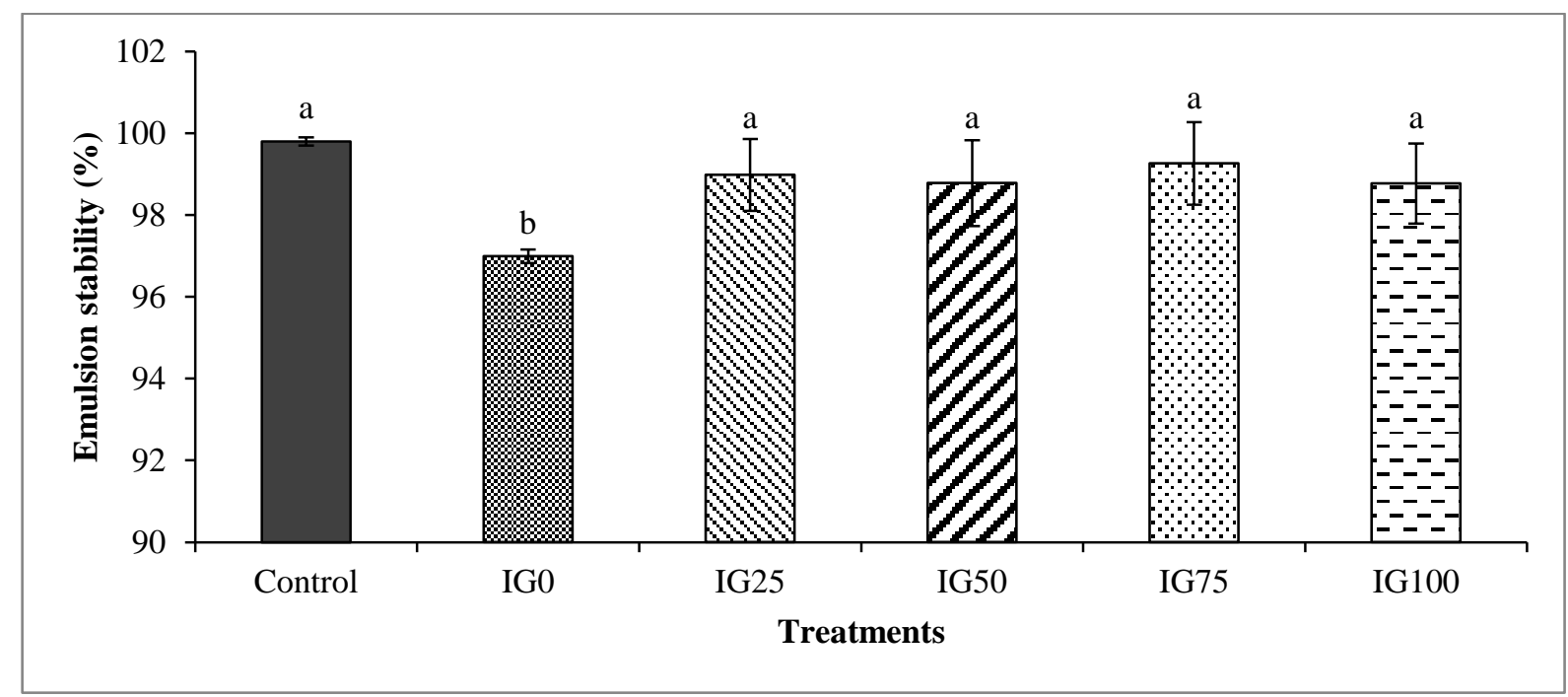

Figure 2. Emulsion stability of tuna roe mayonnaise replacing soybean oil with inulin gel. Bars represent the standard deviation $(n=3)$. Different letters on the bars indicate significant difference $(\mathrm{p}<0.05)$.

\section{3. $p H$ values}

The $\mathrm{pH}$ values of tuna roe mayonnaise replacing soybean oil with inulin gel were shown in Figure 3. The $\mathrm{pH}$ value in the mayonnaise samples was about 3.94 to 3.98, and there was no significant different as a result of inulin replacement ( $p>0.05)$. This result was in agreement with the findings of Bortnowska and Makiewicz [25], who reported that there was no $\mathrm{pH}$ changes in the inulin mayonnaise products compared with original one. In addition, protein objects including roe fish contain more buffering capacity because of some amino acid content such as histidine which acts as $\mathrm{pH}$ regulator [26]. Therefore $\mathrm{pH}$ of the mayonnaise system was quite constant.

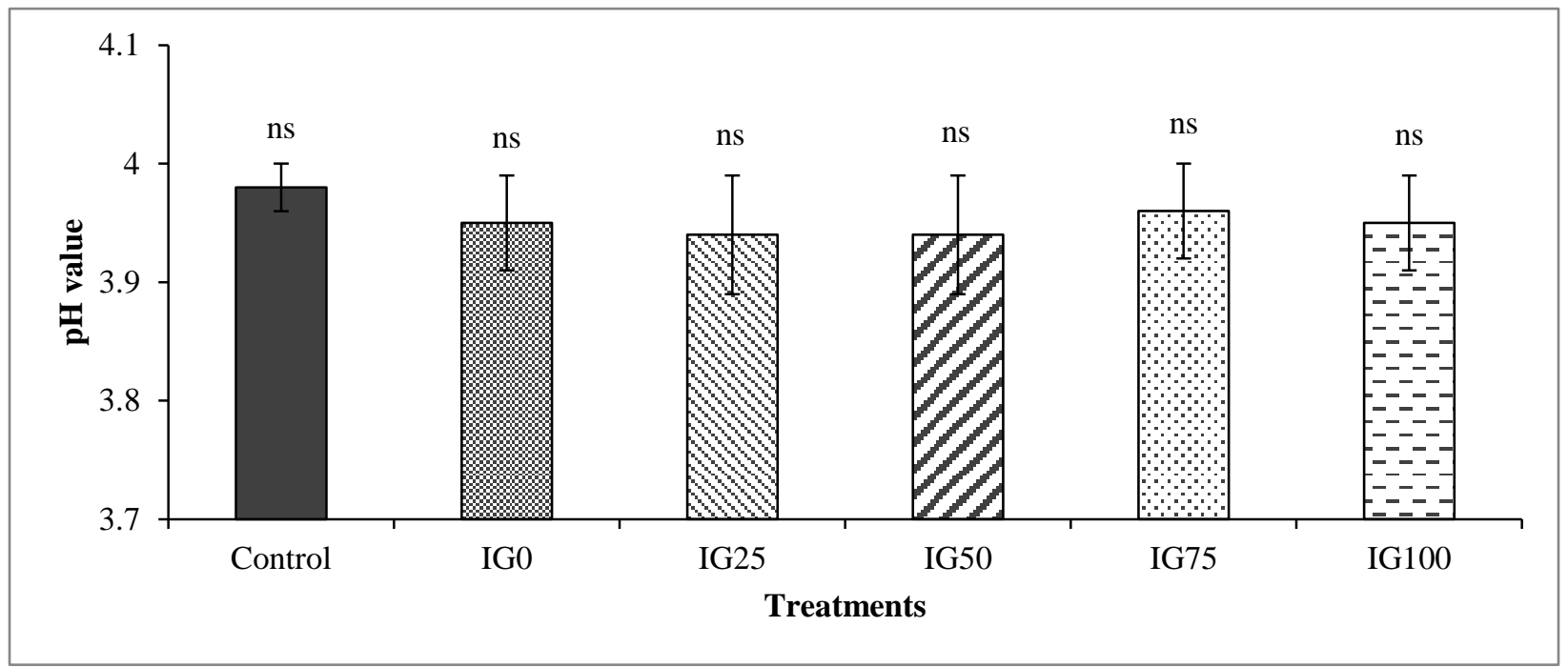

Figure 3. $\mathrm{pH}$ values of tuna roe mayonnaise replacing soybean oil with inulin gel. Bars represent the standard deviation $(n=3)$. ns means not significant difference 


\section{Moisture content}

Moisture content of the tuna roe mayonnaise replacing soybean oil with the inulin gel was shown in Figure 4. It was found that moisture content of the mayonnaise increased as increasing of inulin replacement $(\mathrm{p}<0.05)$ due to higher water content containing in inulin gel. Liu et al. [27] addressed that the moisture content of emulsion product increased with addition of fat replacers particularly carbohydrate or protein-based fat objects.

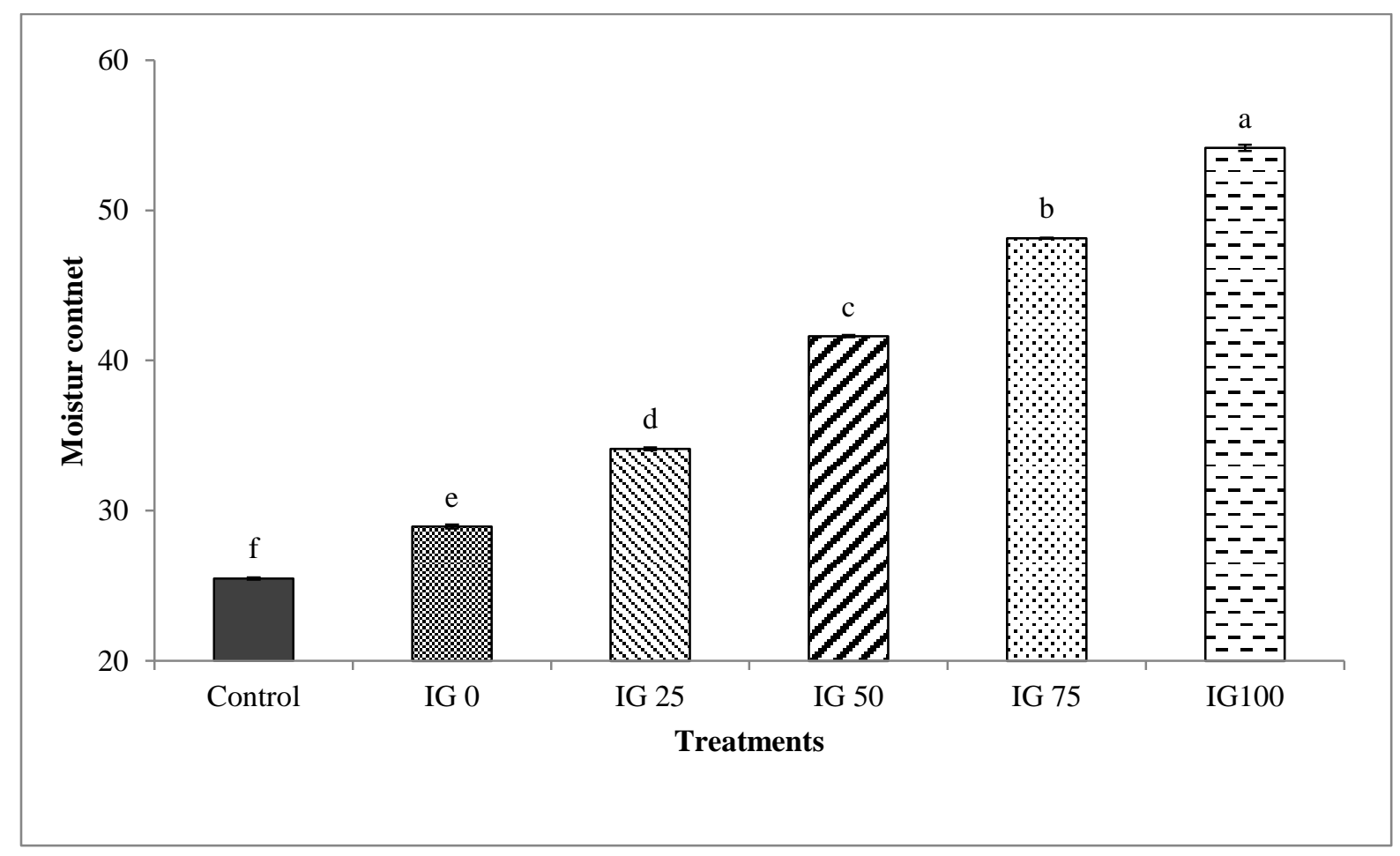

Figure 4. Moisture content of tuna roe mayonnaise replacing soybean oil with inulin gel. Bars represent the standard deviation $(n=3)$. Different letters on the bars indicate significant difference $(\mathrm{p}<0.05)$.

\section{Water activity}

Water activity $\left(\mathrm{a}_{\mathrm{w}}\right)$ is the measurement parameter indicating the amount of free water in a product. The $\mathrm{a}_{\mathrm{w}}$ value of the tuna roe mayonnaise replacing soybean oil with inulin gel was shown in Figure 5. The result showed that control sample gave the lowest $a_{w}$ value (0.921), and significantly increased when substitution of inulin gel increased $(\mathrm{p}<0.05)$. As expected, $\mathrm{a}_{\mathrm{w}}$ of the tuna roe mayonnaises increased with increasing percentage of inulin gel substitution mainly because of the increasing of water content. Actually, $\mathrm{a}_{\mathrm{w}}$ of both inulin gel and tuna roe were 1.000 while egg yolk was 0.995 , which was lower compared with inulin gel and tuna roe $(\mathrm{p}<0.05)$. It pointed out that water in the gel was in a free form which was loosely tapped or absorbed in the gel matrix. Therefore, when solid content including sugar and $\mathrm{NaCl}$ were added and dissolved, $\mathrm{a}_{\mathrm{w}}$ of system was reduced. 


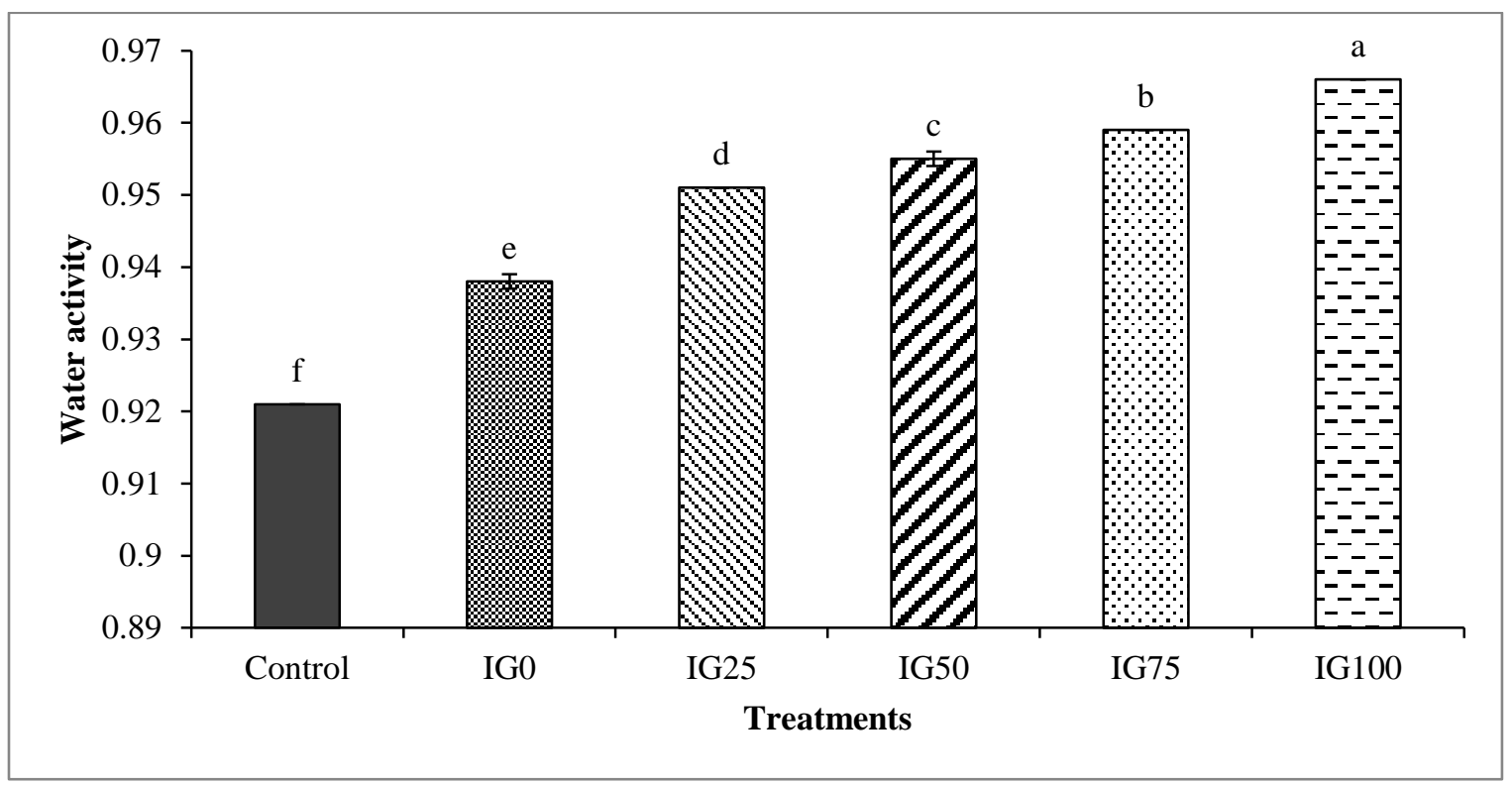

Figure 5. Water activity $\left(a_{w}\right)$ of tuna roe mayonnaise replacing soybean oil with inulin gel. Bars represent the standard deviation $(n=3)$. Different letters on the bars indicate significant difference $(\mathrm{p}<0.05)$.

\section{Peroxide values}

Peroxidation value is a measurement of primary oxidation compounds (hydroperoxides) in the sample. Peroxide value of control sample was $9.94 \pm 2.07 \mathrm{mg}$ hydroperoxide/ $\mathrm{kg}$ sample. It was found that increasing of inulin gel in to the sample seemed to more reduce lipid oxidation as shown in Figure 6. Generally, lipid hydrolysis is facilitated by $\mathrm{H}_{2} \mathrm{O}$ to change triglyceride to diglycerides and monoglyceride, which are prone to oxidize and usually have an adverse impact on emulsion stability (28). However, the lipid oxidation could be reduced when water content particularly as free form, $a_{w}$ was increased. This may due to hydrogen bonding between water and hydroperoxides led to increase of hydroperoxide stability, hydration of transition metals, diffusion and mobilization the metals and dilution effect on prooxidant (29). Additionally, the lesser oil content which was initial substrate sample particularly in IG100, the lower lipid oxidation. Furthermore, Nuchi et al. (30) reported that in emulsion system, transition metals primarily promote oxidation by decomposing lipid hydroperoxides located at the droplet surface into free radicals. Emulsion droplets are surrounded by a membrane of emulsifier molecules. These membranes not only prevent the droplets from coalescing but also may protect lipids from oxidation by acting as a barrier to the penetration and diffusion of molecular species that promote lipid oxidation into the droplets (31). It pointed out that increased inulin gel decreased interactions between lipid and aqueous phase prooxidants leading to lower lipid oxidation product. 


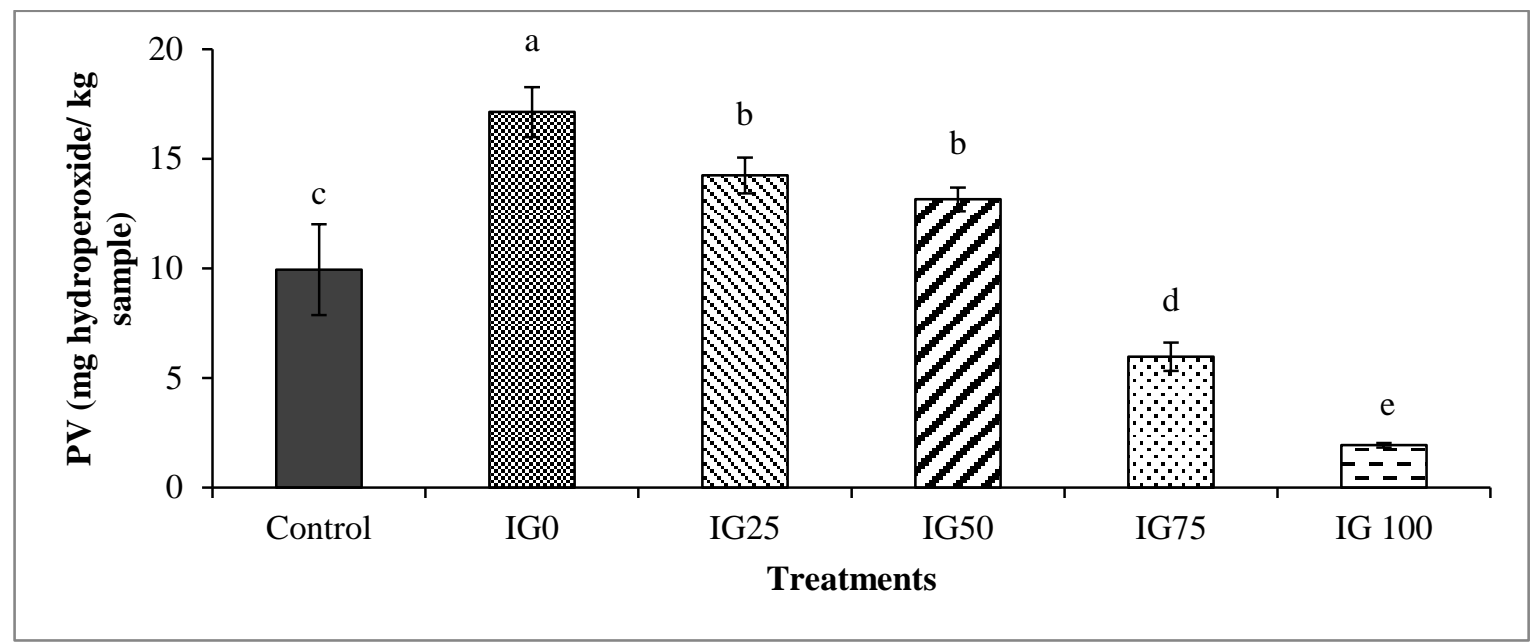

Figure 6. Peroxide values (PV) of tuna roe mayonnaise replacing soybean oil with inulin gel. Bars represent the standard deviation $(n=3)$. Different letters on the bars indicate significant difference $(\mathrm{p}<0.05)$.

\section{Thiobarbituric acid reactive substances}

The TBARS values of the tuna roe mayonnaise replacing soybean oil with inulin gel were shown in Figure 6. The lowest TBARS found in control sample was $1.91 \pm 0.06 \mathrm{mg}$ MDA $/ \mathrm{kg}$ sample. It was found that reducing of oil in to the tuna roe mayonnaise seemed to have no tends in TBARS value, with value in range $8.55-11.43 \mathrm{mg} \mathrm{MDA} / \mathrm{kg}$ sample. This due to complicated food matrix manner. In addition, egg yolk used in this experiment was very fresh and contained low PUFA while tuna roe, a solid waste, is easily to oxidize because it contained high PUFA content and not really fresh (thawed form) as well as application of blancing in preparation tuna roe must induce more lipid oxidation (3). Furthermore, the tuna roe was blended and mixed with other ingredients during making mayonnaise. It meant that oxygenation should be more incorporated. Therefore, it pointed out that the tuna roe played a key role for TBARS value in sample.

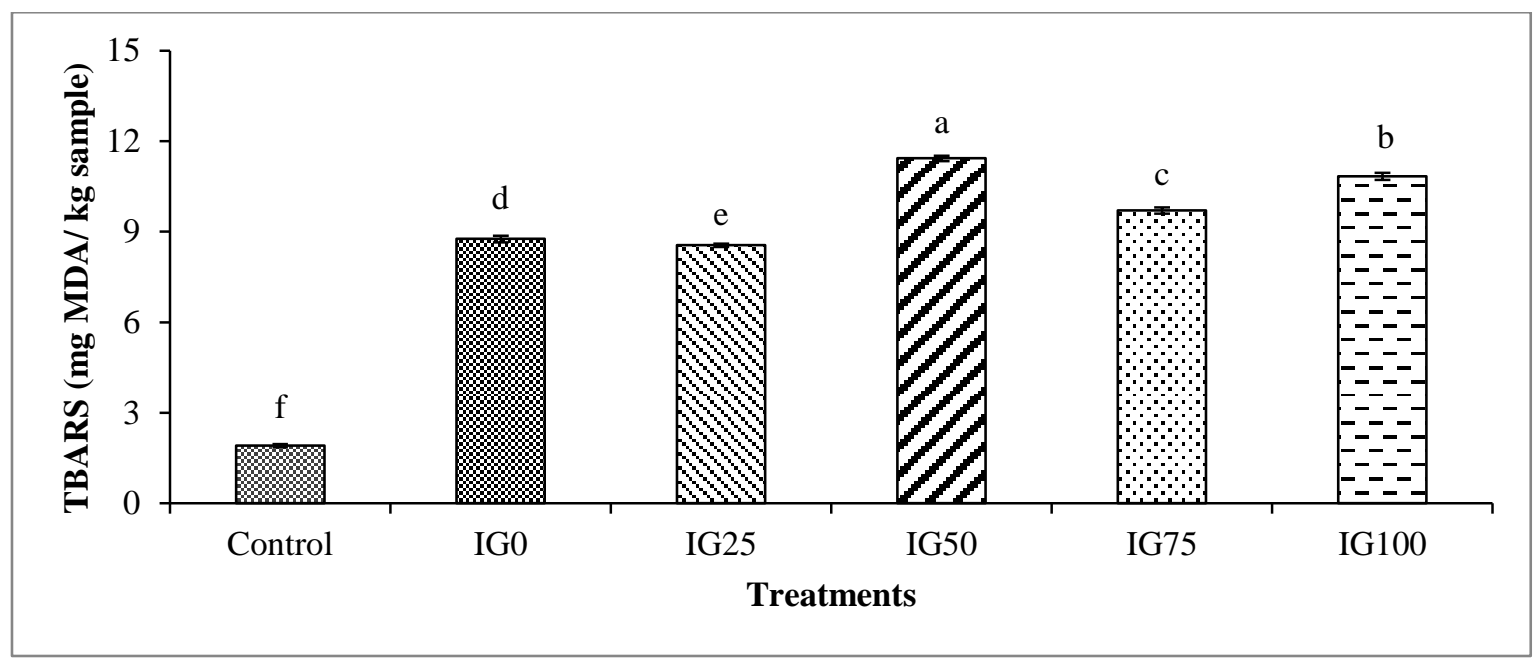

Figure 7. Thiobarbibutiric acid reactive substance (TBARS) of tuna roe mayonnaise replacing soybean oil with inulin gel. Bars represent the standard deviation $(n=3)$. Different letters on the bars indicate significant difference $(\mathrm{p}<0.05)$. 


\section{Microbiological properties}

Based on Thai industrial standard for the salad dressing and mayonnaise products which set up total viable counts $<1000 \mathrm{CFU} / \mathrm{g}$, yeast and mold $<10 \mathrm{CFU} / \mathrm{g}$, coliform $<3 \mathrm{MPN} / \mathrm{g}$ and lactobacillus $<10 \mathrm{CFU} / \mathrm{g}$, there was no doubt for microbiological quality of any mayonnaise either control or treatment samples (Table 2). This may due to high acidity effect of the products which controlled at $\mathrm{pH}$ about 4.0. In addition, it was found that the pretreated tuna roe with soaking in galangal ethanolic extract and blanching at $65^{\circ} \mathrm{C}$ could significantly reduce total viable count to be less than $10 \mathrm{CFU} / \mathrm{g}$. An effectiveness of weak acid as acetic acid to against microbial was due to mainly undissociated acetic acid which was dissociated again in bacterial cell leading to disrupting substrate transport, and oxidative phosphorylation, destroying cell membrane, denature protein compound in DNA, enzymes and organel as so on (32).

Table 2 Total viable count (TVC), yeast and mold, coliforms and lactobacillus of tuna roe mayonnaise replacing soybean oil with inulin gel.

\begin{tabular}{lcccc}
\hline \multicolumn{1}{c}{ Treatment } & $\begin{array}{c}\text { Total viable count } \\
(\mathrm{CFU} / \mathrm{g})\end{array}$ & $\begin{array}{c}\text { Yeast and mold } \\
(\mathrm{CFU} / \mathrm{g})\end{array}$ & $\begin{array}{c}\text { Coliform } \\
(\mathrm{MPN} / \mathrm{g})\end{array}$ & $\begin{array}{c}\text { Lactobacillus } \\
(\mathrm{CFU} / \mathrm{g})\end{array}$ \\
\hline Control & $<10$ & $<10$ & $<3$ & $<10$ \\
IG 0 & $<10$ & $<10$ & $<3$ & $<10$ \\
IG 25 & $<10$ & $<10$ & $<3$ & $<10$ \\
IG 50 & $<10$ & $<10$ & $<3$ & $<10$ \\
IG 75 & $<10$ & $<10$ & $<3$ & $<10$ \\
IG 100 & $<10$ & & $<3$ \\
\hline
\end{tabular}

\section{Sensory evaluation}

It was unsurprising to get the highest score in all attributes from control treatment $(p<0.05)$ as shown in Table 3. However, regardless of control sample, sensory acceptability of the mayonnaise replacing with inulin gel was found in IG0 to IG75. Using a score of 5 as the acceptability limit, it was found that IG100 had lowest score when compared with other samples. The panelists noted that IG100 had a strong fishy odour and rancid smell. Additionally, it was noted that using 50\% inulin for fat replacing seemed to have higher scores and were closer to control group. Moreover, the panelists also stated that the tuna roe mayonnaise produced some distinct smell such as a fishy odor, and had a coarse texture compared with control sample leading to bias feeling. They also advised that if the control was not served, then the score of the tuna roe mayonnaise must be higher. Moreover, the participants stated that the health benefit information should be announced and proposed when the product is launched into a market.

Table 3. Sensory evaluations of tuna roe mayonnaise replacing soybean oil with inulin gel.

\begin{tabular}{lccccc}
\hline \multicolumn{1}{c}{ Treatment } & Appearance & Color & Odor & Taste & $\begin{array}{l}\text { Overall } \\
\text { acceptability }\end{array}$ \\
\hline Control & $8.10 \pm 0.92 \mathrm{a}$ & $8.13 \pm 0.63 \mathrm{a}$ & $7.13 \pm 0.94 \mathrm{a}$ & $8.00 \pm 1.05 \mathrm{a}$ & $7.90 \pm 0.96 \mathrm{a}$ \\
IG 0 & $6.57 \pm 0.77 \mathrm{bc}$ & $6.50 \pm 0.97 \mathrm{~b}$ & $6.07 \pm 1.01 \mathrm{~b}$ & $6.33 \pm 1.09 \mathrm{bc}$ & $6.20 \pm 1.10 \mathrm{~b}$ \\
IG 25 & $6.60 \pm 0.97 \mathrm{bc}$ & $6.80 \pm 1.03 \mathrm{~b}$ & $6.27 \pm 1.01 \mathrm{~b}$ & $6.53 \pm 1.36 \mathrm{~b}$ & $6.37 \pm 1.19 \mathrm{~b}$ \\
IG 50 & $6.97 \pm 0.89 \mathrm{~b}$ & $6.57 \pm 0.86 \mathrm{~b}$ & $6.40 \pm 1.10 \mathrm{~b}$ & $6.63 \pm 1.16 \mathrm{~b}$ & $6.57 \pm 1.10 \mathrm{~b}$ \\
IG 75 & $6.90 \pm 0.76 \mathrm{~b}$ & $6.53 \pm 1.01 \mathrm{~b}$ & $6.10 \pm 0.84 \mathrm{~b}$ & $6.27 \pm 1.05 \mathrm{bc}$ & $6.27 \pm 1.14 \mathrm{~b}$ \\
IG 100 & $6.33 \pm 1.12 \mathrm{c}$ & $6.30 \pm 1.15 \mathrm{~b}$ & $5.50 \pm 0.86 \mathrm{c}$ & $5.80 \pm 1.10 \mathrm{c}$ & $5.47 \pm 1.07 \mathrm{c}$ \\
\hline
\end{tabular}

Means $(\mathrm{n}=30) \pm \mathrm{SD}$ in the same column with different small letters are significantly different $(\mathrm{p}<0.05)$. 


\section{CONCLUSIONS}

Generally, both physical and microbiological qualities of the control sample and the tuna roe substituted with inulin gel as fat replacer were not significantly different. However, tuna roe is a good source of omega 3 fatty acids (DHA and EPA) which are more susceptible to lipid oxidation, as reflected by their high PV and TBARS contents. Additionally, we discovered that the tuna roe mayonnaise in both with and without substituted inulin gel had lower score of sensory acceptability compared with control sample with using egg yolk. Although the sensory score of the tuna roe mayonnaise was not equal to the control one, using 50\% substituted inulin gel (IG50) for fat replacer was selected for next experiment to improve its sensory quality and provide health claims.

List of Abbreviations: PUFA, Polyunsaturated Fatty Acid; EPA, Eicosapentaenoic Acid; DHA, Docosahexonoic Acid; PV, Peroxide Value; TBARS, Thiobarbituric Acid Reactive Substances; TVC, Total Value Count; LAB, Lactic Acid Bacteria; IG0, Inulin Gel; IG50, 50\% Inulin Gel Substitution

Competing interest: None to declare.

\section{Author's contributions:}

Kanrawee Hunsakul, BSc, MSc is a Food Technologist and performed all of the laboratory work for the study and provided statistical analysis and assisted in writing the manuscript.

Sunisa Siripongvutikorn, $\mathrm{PhD}$ is an Assistant Professor of Food Technology. She is principal investigator for this study providing oversight and contributing fundamental conceptualization for the research, writing the grant proposal and manuscript.

Worapong Usawakesmanee, $\mathrm{PhD}$ is a Food Technology. He coordinated the initiatives to accelerate the development and subsequent production of the intervention meal. He also contributed in the study design and assisted in writing the manuscript

Financial sponsor: This article was not sponsored by any company.

Acknowledgements: The authors would like to thank the Graduate School of Prince of Songkla University, Thailand, for the financial support.

\section{REFERENCES}

1. Fisheries Foreign Affairs Division. Information exported fishery product. Available from: http://www.fisheries.go.th/foreign/index.php?option=com_content\&view=category \&id=36\&Itemid=32 2014. Accessed 24 March 2014.

2. Factory information by personal contact, 2014.

3. Intarasirisawat, R., Benjakul, S. and Visessanguan, W. Chemical compositions of the roes from skipjack, tongol and bonito. Food Chem 2011; 124: 1328-1324.

4. Frankel, E.N. Lipid Oxidation. Dundee. The Oily Press. 2005. 
5. McClements, D. Food emulsions: principles, practice, and techniques. 2nd ed. Boca Roton. CRC Press. 2005.

6. Mantzouridou, Fa., Spanou, A. and Kiosseoglou, V. An inulin-based dressing emulsion as a potential probiotic food carrier. Food Res Inter 2012; 46(1): 260-269.

7. Meyer, D., Bayarri, S., Tárrega, A. and Costell, E. Inulin as texture modifier in dairy products. Food Hydrocoll 2011; 25(8): 1881-1890.

8. Blecker C., Chevalier, J.P., Herck, J.C., Fougnies, C., Deroanne, C. and Paquot, M. Inulin: Its Physicochemical Properties and Technological Functionality. Recent Res Devel Agric Food Chem 2001; 5: 125-131.

9. Kim, Y., Faqih, M.N. and Wang, S.S. Factors affecting gel formation of inulin. Carbohyd. Polym 2001; 46(2): 135-145.

10. Mun, S., Kim, Y.L., Kang, C.G., Park, K.H., Shim, J.Y. and Kim, Y.R. 2009. Development of reduced-fat mayonnaise using $4 \alpha$ GTase-modified rice starch and xanthan gum. Inter J Biol Macromol 2009; 44(5): 400-407.

11. Benjakul, S., Seymour, T.A., Morrissey, M.T. and An, H. Physicochemical changes in pacific whiting muscle protein during iced storage. J Food Sci 1997; 62(4):729-733.

12. AOAC. Official Method of Analysis. 16th ed. Association of Official Analytical Chemists. Washington DC. 2000.

13. Tong, L. M., Sasaki, S., McClements, D. J. and Decker, E. A. Antioxidant activity of whey in a salmon oil emulsion. J Food Sci 2000; 65(8): 1325-1329.

14. Egan, H., Kirk, R.S., and Sawyer, R. Pearson's Chemical Analysis of Foods. London. Churchill Livingstone. 1981.

15. Bacteriological Analytical Manual (BAM). Chapter 3: Aerobic plate count. U.S. Food and Drug Administration. Available from: http://www.fda.gov/Food/FoodScience Research/LaboratoryMethods/ucm063346.htm 2001. Accessed 10 May 2014.

16. Bacteriological Analytical Manual (BAM). Chapter 18: Yeasts, Molds and Mycotoxins. U.S. Food and Drug Administration. Available from: http://www.fda.gov/Food /FoodScienceResearch/LaboratoryMethods/ucm071435.htm 2001. Accessed 10 May 2014.

17. Bacteriological Analytical Manual (BAM). Chapter 4: Enumeration of Escherichia coli and the Coliform Bacteria. U.S. Food and Drug Administration. Available from: http://www.fda.gov/Food/FoodScience Research/LaboratoryMethods/ucm064 948.htm 2001. Accessed 10 May 2014.

18. Bacteriological Analytical Manual (BAM). Chapter 21A: Examination of Canned Foods. U.S. Food and Drug Administration. Available from: http://www.fda.gov /Food/FoodScienceResearch/LaboratoryMethods/ucm109398.htm 2001. Accessed 10 May 2014.

19. Meilgaard, M., Civille, G.V. and Carr, B.T. Sensory Evaluation Technique. 3rd ed. Boca. Paton. CRC Press Inc. 1999.

20. Steel, R. G. D. and Torrie, J. H. Principles and procedures of statistics: A Biometrical Approach. 2nd ed. New York. McGraw-Hill Book Company. 1980. 
21. Li-Chang, E. C. Y. and Kim, H. O. Structure and chemical composition of eggs. In Egg Bioscience and Biotechnology. 1st edition. Edited by Mine, Y. USA. John Wiley \& Sons Inc; 2008: 1-96.

22. Kanner, J. and Harel, S. Initiation of membranal lipid peroxidation by activated metmyoglobin and methemoglobin. Arch Biochem Biophys 1985; 237(2): 314-321.

23. Fox, J. B. The Pigments of Meat. In The Science of Meat and Meat Products. 3rd edition. Edited by Price J. F. and Schweigert, B. S. Westport, Connecticut. Food and Nutrition Press; 1987: 193-215.

24. Hultin, H.O. 1988. Potential lipid oxidation problems in fatty fish processing. In Fatty fish utilization: Upgrading from feed to food; Proceeding of a national technical conference. Edited by Davis, N. UNC Sea grant college program, Raleigh, N.C. 1988: $185-223$

25. Bortnowska, G. and Makiewicz, A. Technological utility of guar gum and xanthan gum for the production of low-fat inulin-enriched mayonnaise. Acta Sci Pol 2006; 5(2): 135146.

26. Inoue, K., Morioka, K., Shioya, I., Mitsuboshi, T., Itoh, Y., Obtake, A. and Satake, T. Effect of deep seawater acclimation on components and texture of the muscle red sea bream. Fish Sci 1998; 64(5): 804-807.

27. Liu, H., Xu, X. M. and Guo, S. D. Rheological, texture and sensory properties of low-fat mayonnaise with different fat mimetics. LWT-Food Sci Technol 2007; 40(6): 946-954.

28. Ford, L.D., Borwankar, R.P., Pechak, D. and Schwimmer, B. Dressings and sauces. In Food Emulsions. 3rd edition. Edited by Friberg, S.E., Larsson, K. and Sjöblom, J. New York. Marcel Dekker; 2003: 525-572.

29. Frankel EN. Lipid oxidation. Dundee. The Oil Press. 1998.

30. Nuchi, C.D., Hernandez, P., McClements, D.J. and Decker, E.A., 2002. Ability of lipid hydroperoxides to partition into surfactant micelles and alter lipid oxidation rate in emulsions. J Agric Food Chem 2002; 50(19): 5445-5449.

31. Coupland, J. N. and McClements, D. J. Lipid oxidation in food emulsions. Trends Food Sci Technol 1996; 7(3): 83-91.

32. Larson, E.L. and Morton, H.E. Alcohol. In Disinfection, sterilization, and preservation. 5th edition Edited by Block, S.S. Philadelphia. Pa. Lea and Febiger. 1991: 191-203. 